\title{
Concomitant Radiotherapy and Chemotherapy for High-Risk Nonmelanoma Skin Carcinomas of the Head and Neck
}

\author{
Smith Apisarnthanarax, ${ }^{1}$ Nirav Dhruva, ${ }^{2}$ Farhad Ardeshirpour, ${ }^{3}$ \\ Joel E. Tepper, ${ }^{4}$ Carol G. Shores, ${ }^{3}$ Julian G. Rosenman, ${ }^{4}$ William W. Shockley, ${ }^{3}$ \\ Michele C. Hayward, ${ }^{2}$ and D. Neil Hayes ${ }^{2}$ \\ ${ }^{1}$ Department of Radiation Oncology, University of Pennsylvania, Abramson Cancer Center, Philadelphia, PA 19104, USA \\ ${ }^{2}$ Department of Medical Oncology, University of North Carolina Hospitals, Lineberger Comprehensive Cancer Center, Chapel Hill, \\ NC 27599, USA \\ ${ }^{3}$ Department of Head and Neck Surgery, University of North Carolina Hospitals, Lineberger Comprehensive Cancer Center, Chapel Hill, \\ NC 27599, USA \\ ${ }^{4}$ Department of Radiation Oncology, University of North Carolina Hospitals, Lineberger Comprehensive Cancer Center, Chapel Hill, \\ NC 27599, USA
}

Correspondence should be addressed to Smith Apisarnthanarax, apisarns@uphs.upenn.edu

Received 14 May 2011; Accepted 27 June 2011

Academic Editor: Michael Veness

Copyright () 2011 Smith Apisarnthanarax et al. This is an open access article distributed under the Creative Commons Attribution License, which permits unrestricted use, distribution, and reproduction in any medium, provided the original work is properly cited.

\begin{abstract}
Background. To report on the use and feasibility of a multimodality approach using concomitant radiotherapy and chemotherapy in patients with high-risk nonmelanoma skin carcinoma (NMSC) of the head and neck. Methods. Records of patients with NMSC of the head and neck who received concomitant CRT at the University of North Carolina between 2001 and 2007 were reviewed. Results. Fifteen identified patients had at least one of the following high-risk factors: T4 disease (93\%), unresectability (60\%), regional nodal involvement $(40 \%)$, and/or recurrence $(47 \%)$. Ten patients were treated in the definitive setting and five in the postoperative setting. Platinum based chemotherapy was given in 14 (93\%) patients. Ten of fifteen (67\%) patients completed all planned chemotherapy treatments, and thirteen patients $(87 \%)$ completed at least $80 \%$ of planned chemotherapy. Mild radiation dermatitis occurred in all patients and reached grade 3 in 13\% of patients. No patients experienced grade 4 or 5 toxicity. With a median followup of 31 months in surviving patients, the 2-year actuarial locoregional control and relapse-free survival were $79 \%$ and $49 \%$, respectively. Conclusions. Definitive or postoperative chemoradiotherapy for patients with locally advanced or regionally metastasized NMSC of the head and neck appears feasible with acceptable toxicities and favorable locoregional control.
\end{abstract}

\section{Introduction}

Nonmelanoma skin carcinoma (NMSC) is the most common malignancy worldwide with an incidence of over 1.3 million in the United States, making it an important global public health issue [1]. NMSCs arise in anatomic areas subject to frequent sun exposure, most commonly in the head and neck [2]. When diagnosed at an early stage, localized squamous and basal cell carcinomas of the skin have high cure rates of greater than $90 \%$ with local treatments such as surgical excision, Mohs' chemosurgery, electrocautery, and radiotherapy (RT) $[3,4]$.
However, subsets of these cancers can be biologically and clinically aggressive with a greater propensity for local, regional nodal, and, to a lesser extent, distant metastatic spread [5]. These "high-risk" NMSCs have been reported to be associated with certain adverse prognostic features, including large tumor size, high grade, deep invasion, regional nodal involvement, recurrent disease, perineural invasion, and immunosuppression [6-8].

The optimal management of these high-risk tumors is unclear due to the paucity of data. Despite aggressive treatment with surgery and/or RT, locoregional failures represent the first site of recurrence in the majority $(70-80 \%)[9,10]$ of 
these patients and are associated with considerable morbidity and disease-related mortality [3, 11-14]. Optimizing locoregional control, therefore, may significantly improve longterm clinical outcomes. One proposed method of intensifying locoregional treatment is through a multidisciplinary approach of integrating surgery, RT, and chemotherapy in various combinations.

There has been increasing interest in the use of chemotherapy for NMSCs [15]. The addition of chemotherapy for tumor radiosensitization to increase locoregional tumor control is an approach that could potentially improve outcomes in these high-risk patients. The superiority of chemoradiotherapy (CRT) over RT alone has been established for squamous cell carcinomas in many other tumor sites, including mucosal head and neck [16-19], esophageal [20], cervical [21-23], and anal carcinomas [24, 25]. However, the role of adding chemotherapy to RT in high-risk NMSCs has largely been unexplored with evidence limited to isolated case reports [26, 27].

The feasibility and toxicities of combining a systemic radiosensitizing agent with $\mathrm{RT}$ in this group of patients are unknown, particularly because these patients possess patient and tumor characteristics, such as older age and superficial tumor location, which may confer different toxicities compared to those experienced in patients treated for mucosal tumors of the head and neck. We report our institutional experience on the feasibility, toxicity, and outcomes of treating high-risk NMSCs of the head and neck with concomitant CRT.

\section{Patients and Methods}

Patients with NMSCs of the head and neck treated with concomitant CRT from 2001 to 2007 were identified by reviewing the head and neck database at the University of North Carolina Hospitals (Lineberger Comprehensive Cancer Center, Chapel Hill, NC, USA). Patients with histologies other than squamous or basal cell carcinoma and NMSC of the lip were excluded, since these patients were treated primarily with surgery alone at our institution. Patients were evaluated by a multimodality team consisting of the head and neck surgeon, medical oncologist, and radiation oncologist. For comparison, records of patients with NMSC of the head and neck treated with RT alone were also evaluated from 1990 to 2007. To select patients with high-risk features, patients treated only for cosmetic purposes or personal preference were excluded from the RT-alone patient group.

Clinical and histopathologic data were gathered on patient characteristics, treatment delivered, acute and late toxicities, and treatment outcomes. Patients were staged according to the AJCC cancer staging guidelines for carcinoma of the skin, excluding eyelid, vulva, and penis [28]. Toxicities were scored according to the Common Terminology Criteria for Adverse Events (CTCAE), version 3.0, for chemotherapy and to the Radiation Therapy Oncology Group (RTOG) criteria for RT. Locoregional failure was defined as the reappearance of tumor in the original tumor bed or development of cervical or intraparotid node metastases after treatment. Survival outcomes were measured from the time of treatment start. This study was approved by the University of North Carolina Biomedical Institutional Review Board.

Differences in means were tested by the Welch twosample $t$-test. Rates of locoregional control were estimated according to the method of cumulative incidence [29], and differences were assessed by the Gray's test [30]. Rates of relapse-free survival and overall survival were estimated according to the Kaplan-Meier method [31], and differences between groups were assessed by log-rank statistic [32]. Hazard ratios were calculated using the Cox proportional hazard method. Differences in proportions were assessed by the 2-sample test for equality of proportions with continuity correction. All $P$ values reported are for 2 -sided tests. The statistical software package R 2.9.1 was used for all statistical testing except for rendering of the Kaplan-Meier plots which were performed in GraphPad Prism [33].

\section{Results}

3.1. Patient Characteristics. Fifteen patients with NMSC of the head and neck treated with concomitant CRT and 30 patients treated with RT-alone were identified. Median followup in surviving patients was 31 months (range, 971 months) for CRT patients and 35 months (range, 2-223 months) for RT-alone patients. Nearly all patients (89\%) were male and Caucasian (98\%) (Table 1). The median age (66 years) in these patients is expected given the typical age at presentation for NMSCs. The majority of patients in both groups had squamous cell histology (73\% CRT, 63\% RT). Treatment was considered curative in 29 patients and palliative for aggressive local control in 1 patient for $\mathrm{RT}$ alone patients. All patients treated with CRT were treated with curative intent. No patient had immunosuppression.

Patients treated with CRT had at least one of the following high-risk factors: T4 disease (93\%), unresectability $(60 \%)$, regional nodal involvement $(40 \%)$, and/or recurrence $(47 \%)$. Overall, patients in the CRT group possessed more high-risk tumor features compared to RT patients: large tumor size ( $\mathrm{T}$ stage), nodal involvement, unresectable tumors, bone invasion, soft tissue invasion, extracapsular extension, multiple recurrences, and high-grade status. Of these adverse factors, T stage, unresectability, and bone invasion were statistically different. All patients except 1 in the CRT group had T4 disease (93\%) compared to $47 \%$ in the RT group. In parallel with the differences in resectability and T stage between the two groups, patients treated with CRT tended to be treated in the definitive treatment setting (67\%) compared to the postoperative setting (50\%) in RT-treated patients. An example of a patient treated with CRT is shown in Figure 1.

3.2. Treatment Delivered. RT was delivered daily for 5 days a week. The median dose of radiation to gross disease was $70 \mathrm{~Gy}$ (range: 58 to $75 \mathrm{~Gy}$ ) in 1.8 to $2 \mathrm{~Gy}$ fractions. One patient was planned to receive $70 \mathrm{~Gy}$, but only received 58 Gy due to treatment toxicity. For subclinical (microscopic) disease, the median radiation dose was $50 \mathrm{~Gy}$ (range: 46 to $61 \mathrm{~Gy}$ ) in 1.8 to $2.0 \mathrm{~Gy}$ fractions. Photons only were delivered in 3 patients and a combination of photons and electrons in 
TABLE 1: Patient and primary tumor characteristics.

\begin{tabular}{|c|c|c|}
\hline & \multicolumn{2}{|c|}{ No. (\%) } \\
\hline & CRT & RT \\
\hline Total number & 15 & 30 \\
\hline Mean age (yrs) & 65 (range, 47-84) & 66 (range, 48-89) \\
\hline \multicolumn{3}{|l|}{ Gender } \\
\hline Male & 14 & 26 \\
\hline Female & 1 & 4 \\
\hline \multicolumn{3}{|l|}{ Histology } \\
\hline Squamous cell & 11 & 19 \\
\hline Basal cell & 4 & 11 \\
\hline \multicolumn{3}{|l|}{ Location } \\
\hline Cheek & 3 & 2 \\
\hline Ear & 2 & 5 \\
\hline Eye & 1 & 4 \\
\hline Forehead & 2 & 4 \\
\hline Neck & 1 & 3 \\
\hline Nose & 2 & 1 \\
\hline Preauricular & 2 & 7 \\
\hline Scalp & 2 & 4 \\
\hline \multicolumn{3}{|l|}{ T stage } \\
\hline $\mathrm{T} 1$ & 0 & 1 \\
\hline $\mathrm{T} 2$ & 0 & 4 \\
\hline T3 & 1 & 2 \\
\hline $\mathrm{T} 4$ & 14 & 14 \\
\hline $\mathrm{Tx}$ & 0 & 9 \\
\hline \multicolumn{3}{|l|}{$\mathrm{N}$ stage } \\
\hline N0 & 9 & 22 \\
\hline N1 & 6 & 8 \\
\hline \multicolumn{3}{|l|}{ Presentation } \\
\hline Primary & 8 & 11 \\
\hline Recurrent & 7 & 19 \\
\hline \multicolumn{3}{|l|}{ Primary treatment } \\
\hline Definitive & 10 & 10 \\
\hline Postoperative & 5 & 20 \\
\hline \multicolumn{3}{|l|}{ Tumor features } \\
\hline Unresectable & $9(60)$ & $7(23)$ \\
\hline Bone invasion & $8(53)$ & $6(20)$ \\
\hline Nerve invasion & $3(20)$ & $8(27)$ \\
\hline Soft tissue invasion & $7(47)$ & $8(27)$ \\
\hline Positive margins & $2(40)^{*}$ & $9(45)^{*}$ \\
\hline ECE & $2(13)$ & $2(7)$ \\
\hline Multiple recurrence & $3(20)$ & $1(3)$ \\
\hline High grade $^{\dagger}$ & $9(90)^{\dagger \dagger}$ & $8(62)^{\dagger \dagger}$ \\
\hline
\end{tabular}

${ }^{*}$ Postoperative patients, ${ }^{\dagger}$ moderately to poorly differentiated, ${ }^{\dagger \dagger}$ available tumor grade. CRT, chemoradiotherapy; RT, radiotherapy alone; ECE, extracapsular extension.

12 patients. All patients were treated using CT-based threedimensional treatment planning. Four patients received intensity-modulated radiation therapy (IMRT), primarily for parotid gland sparing. Tissue-equivalent bolus was used in 8 patients to increase the skin surface dose to the tumor.

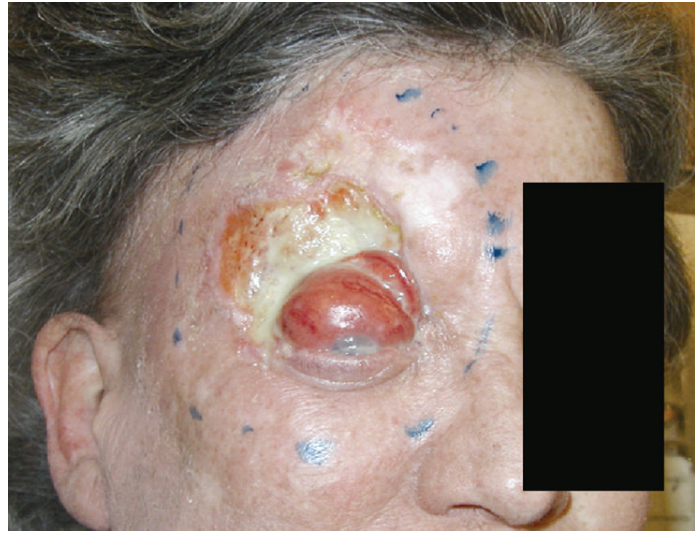

FIGURE 1: Patient treated with concomitant chemoradiotherapy: 60 -year-old white female with an unresectable locally advanced T4 basal carcinoma of the right forehead involving the frontal sinus, lateral orbit, extraocular muscles, and eyelid. She received 70 Gy of radiation given concomitantly with weekly cisplatin $30 \mathrm{mg} / \mathrm{m}^{2}$.

In each case, the decision to offer chemotherapy in combination with RT was made at the recommendation of the multidisciplinary head and neck tumor board and in agreement between the treating medical oncologist and radiation oncologist based on overall patient risk. The chemotherapy regimens employed were at the discretion of the treating medical oncologist. A platinum-based regimen was given concomitantly with RT in 14 of 15 (93\%) patients. Weekly cisplatin $\left(20-30 \mathrm{mg} / \mathrm{m}^{2}\right.$ in 8 patients) or weekly carboplatin (AUC 2 in 2 patients) was used as the sole radiosensitizer in 10 patients, while 3 patients received two agents concomitantly (carboplatin and 5-FU, cisplatin and 5-FU, carboplatin and paclitaxel). One patient received oral therapy with capecitabine, while another received cisplatin $100 \mathrm{mg} / \mathrm{m}^{2}$ delivered every 3 weeks.

3.3. Treatment Tolerance and Toxicity. In CRT patients, chemotherapy was well tolerated overall with 10 of 15 (67\%) patients completing all planned treatments. Thirteen of fifteen $(87 \%)$ patients completed at least $80 \%$ of planned chemotherapy and fourteen of fifteen (93\%) completed all planned courses of radiation. Two patients had hematologic toxicity that precluded one cycle of therapy (one patient had a platelet count of 89,000 and one patient had a WBC count of 1.7 with ANC 1.0), while one patient missed one treatment due to nonadherence. The remaining 2 patients missed treatment because of grade 3 mucositis or delirium. Every patient who did not complete all treatments $(n=5)$ received weekly carboplatin or cisplatin.

During concomitant chemotherapy, no patient experienced grade 4 or 5 acute toxicity (Table 2). The most common acute toxicity was radiation dermatitis, which occurred in all 15 patients and was mild (grade 1 or 2) in nearly all patients $(87 \%)$. Only 2 patients $(13 \%)$ experienced grade 3 dermatitis that required radiation treatment breaks of 2 and 6 days, respectively. In one patient, the cheek and maxillary sinus was treated with mixed photons and electrons concomitantly. The other patient was treated with 
TABLE 2: Overall toxicity in chemoradiotherapy patients.

\begin{tabular}{|c|c|c|c|c|}
\hline \multirow{2}{*}{ Toxicity } & \multicolumn{3}{|c|}{ Grade } & \multirow{2}{*}{ Total No. } \\
\hline & 1 & 2 & 3 & \\
\hline Dermatitis & 3 & 10 & 2 & 15 \\
\hline Mucositis & 0 & 4 & 1 & 5 \\
\hline Conjunctivitis & 2 & 1 & 0 & 3 \\
\hline Keratitis & 1 & 0 & 2 & 3 \\
\hline Xerostomia & 3 & 1 & 0 & 4 \\
\hline Altered mental status & 0 & 0 & 1 & 1 \\
\hline Hearing loss & 0 & 1 & 0 & 1 \\
\hline Tinnitus & 0 & 1 & 0 & 1 \\
\hline Nausea & 4 & 1 & 0 & 5 \\
\hline Vomiting & 1 & 1 & 0 & 2 \\
\hline Dysphagia & 1 & 0 & 0 & 1 \\
\hline Odynophagia & 2 & 0 & 0 & 2 \\
\hline Dysgeusia & 1 & 3 & 0 & 4 \\
\hline Anorexia & 0 & 2 & 0 & 2 \\
\hline Weight loss & 0 & 4 & 0 & 4 \\
\hline Fatigue & 5 & 2 & 0 & 7 \\
\hline Creatinine elevation & 1 & 0 & 0 & 1 \\
\hline Hypocalcemia & 1 & 1 & 0 & 2 \\
\hline Hypomagnesemia & 4 & 1 & 0 & 5 \\
\hline Hyponatremia & 1 & 0 & 0 & 1 \\
\hline Anemia & 3 & 0 & 0 & 3 \\
\hline Leukopenia & 1 & 2 & 2 & 5 \\
\hline Lymphopenia & 2 & 2 & 4 & 8 \\
\hline Neutropenia & 1 & 3 & 0 & 4 \\
\hline Thrombocytopenia & 3 & 0 & 0 & 3 \\
\hline
\end{tabular}

electrons to the primary forehead site and photons to the neck via IMRT. Tissue-equivalent bolus and concomitant weekly carboplatin was used in both of these patients. Six of the other eight patients in which bolus was used developed grade 2 dermatitis.

Mucositis occurred in 5 patients (33\%), reaching grade 3 in only 1 patient (7\%). This patient was treated with extensive radiation fields encompassing nearly the entirety of his left face, including the orbit and maxillary sinus, along with weekly cisplatin. Grade 3 keratitis occurred in 2 patients who had tumor directly involving or adjacent to the orbits, which unavoidably received the full prescribed dose (70 Gy and $50.4 \mathrm{~Gy}$, resp.). One patient, aged 84 , experienced acute altered mental status changes that required hospitalization for grade 3 delirium. His treatment with concomitant RT and weekly carboplatin was stopped early because of this toxicity.

Grade 3 leukopenia and lymphopenia were observed in 2 and 4 patients, respectively. One patient had a grade 1 creatinine elevation prompting change in regimen from cisplatin $30 \mathrm{mg} / \mathrm{m}^{2}$ to carboplatin AUC thrice weekly. Nausea, vomiting, and fatigue were limited to grade 1 or 2 toxicities, and no patient had grade 3 or 4 electrolyte abnormalities.

Serious late toxicities were rare, occurring in only 2 patients. One patient developed grade 3 osteoradionecrosis of the temporal bone, and another patient experienced

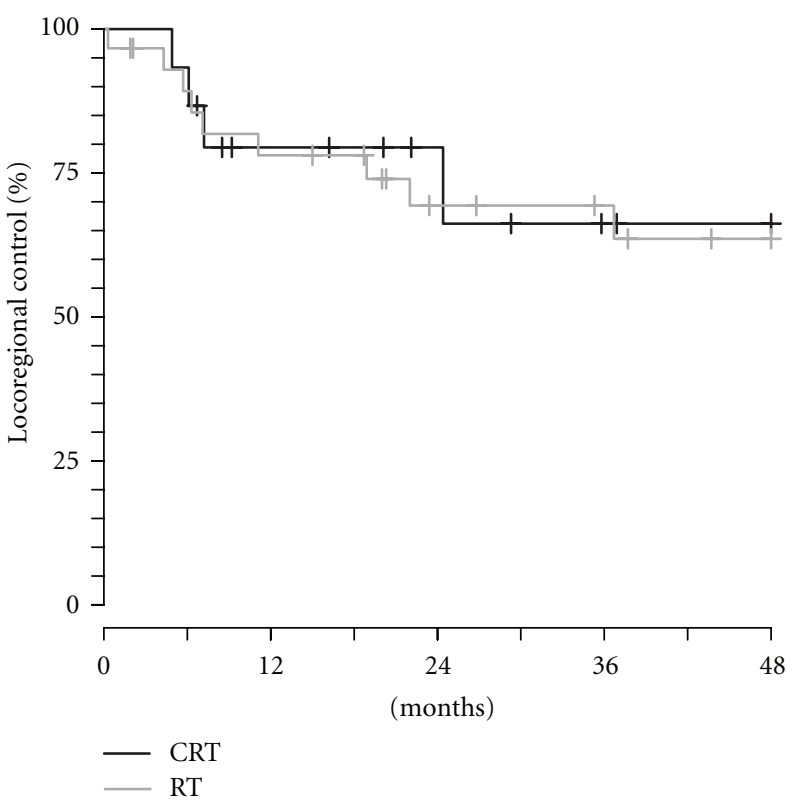

FIgURE 2: Rates of locoregional control in chemoradiotherapy (CRT) and radiotherapy alone (RT) treated patients.

grade 3 chronic otitis media with associated hearing loss. These toxicities were expected because these normal tissue structures were within the high-risk radiation target volumes and received the full prescribed dose.

3.4. Treatment Outcomes. The estimated 2-year locoregional control rates were $79 \%$ for CRT and $69 \%$ for RT patients (Figure 2). The median time to recurrence was 7 months, and greater than $85 \%$ of the failures occurred within 24 months of treatment. The estimated 2-year relapse-free survival rates for the CRT and RT groups were $49 \%$ and $60 \%$, respectively (Figure 3). The estimated 2-year overall survival rates were $65 \%$ (CRT) and $86 \%$ (RT). Of those who died, 5 patients died with recurrent disease, and 2 patients died without evidence of disease.

On univariate analysis for relapse-free survival on all patients, there was a trend towards decreased relapse-free survival for soft tissue and nerve invasion, nodal involvement, and positive margins, but these were not statistically significant (Table 3 ). The only statistically significant factor in the univariate analysis was bone invasion (HR, 5.25; $P<$ 0.01).

On multivariate analysis, both bone invasion (HR, 9.43; CI, 2.8-32; $P<0.01)$ and nodal involvement (HR, 2.60; CI, 1.3-5.1; $P=0.01)$ were highly statistically significantly associated with worse outcome. As previously noted, bone invasion was associated with the decision to add chemotherapy to RT. Therefore, we investigated the potential confounding on estimates of treatment effect by bone invasion status. When controlling for bone invasion and nodal involvement by Cox proportional hazards modeling, we detected a trend toward clinical benefit of combined modality CRT over RT alone for relapse-free survival (HR, 2.72; CI 7.9-9.3; $P=0.11$ ). Patients with bone invasion 


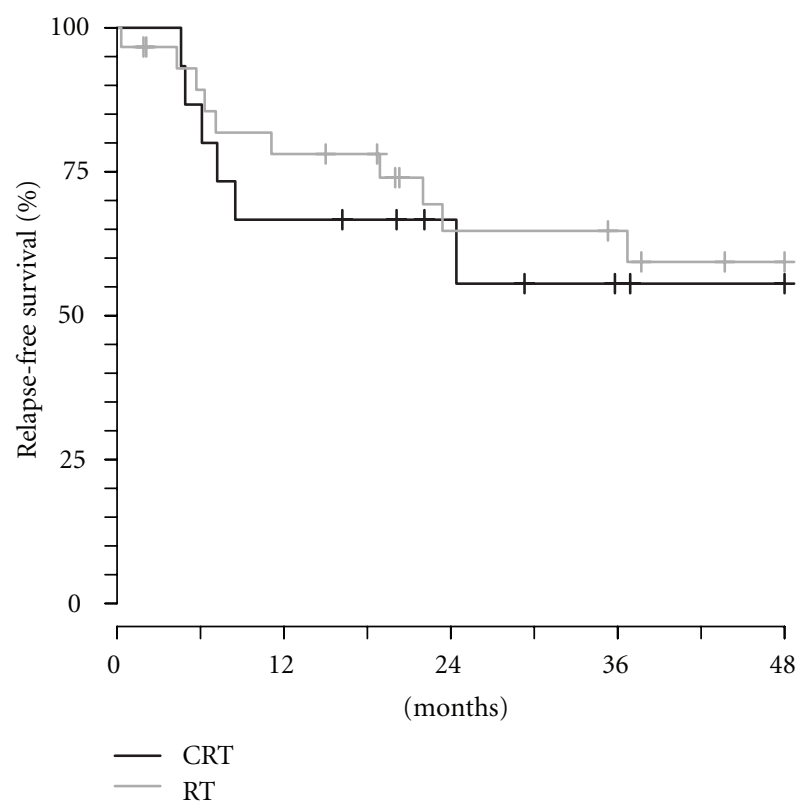

FIgure 3: The Kaplan Meier estimates of relapse-free survival. CRT: chemoradiotherapy; RT: radiotherapy.

had poor relapse-free survival rates in both treated groups ( $25 \%$ at 3 years), whereas patients without bone invasion had improved outcomes $(86 \%$ and $68 \%$ at 3 years for CRT and RT, resp.) (Figure 4).

3.5. Patterns of Failure. Of the 6 patients who developed recurrences after treatment with CRT, 2 patients developed distant failures (dermal metastasis and lung, bones, adrenals); both patients had advanced nodal disease at diagnosis (Table 4). Four local or regional failures were observed in the CRT-treated patients; three were isolated local failures and one was both local and regional failure.

\section{Discussion}

Although NMSC is common worldwide, the prevalence of the most aggressive forms of the disease is unknown, as most cancer surveillance registries do not track NMSC. We estimate that approximately $2-4 \%$ (or 6 patients/year) of all head and neck tumors treated at our institution have a diagnosis of NMSC over the years 2001 to 2007, making this an uncommon, but not rare, disease in our practice. Currently, no clear established role exists for chemotherapy in the definitive or adjuvant treatment of NMSCs, either alone or in combination with RT or surgery. This study is the first report on multiple patients with high-risk NMSCs of the head and neck treated with concomitant RT and chemotherapy.

Our experience suggests that delivering chemotherapy concomitantly with RT is feasible and generally well tolerated with minimal morbidity as delivered in our patient population. Many of the chemotherapy regimens used in our patients have a history of acceptable tolerability and success for other cancers that employ CRT, most notably mucosal head and neck cancer. Nearly all patients were able to

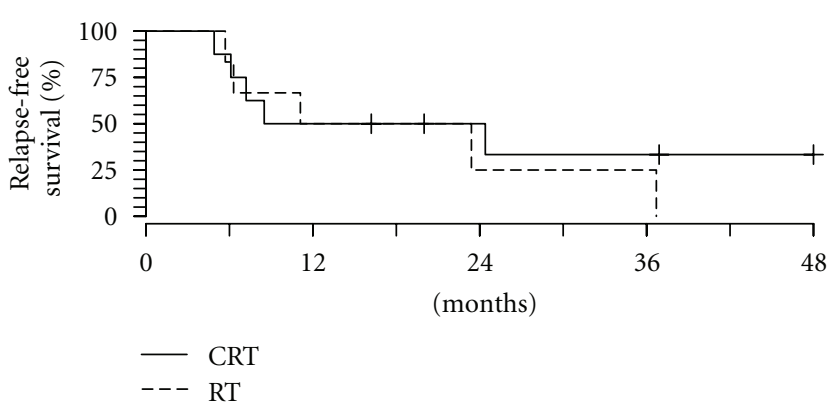

(a)

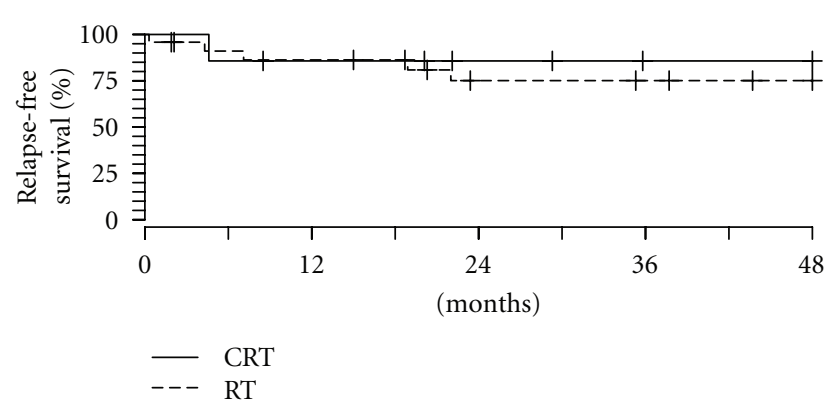

(b)

Figure 4: Estimated relapse-free survival in patients with bone invasion (a) and without bone invasion (b) treated with chemoradiotherapy (CRT) and radiotherapy (RT).

complete the planned therapy: $87 \%$ of patients completed at least $80 \%$ of the planned chemotherapy treatments and 93\% completed the planned radiation treatments. This compares favorably to previous experience of CRT using similar chemotherapy regimens in other malignancies.

Skin toxicity was an important end-point to evaluate because one of the primary goals in treating many of these patients was to maximize the radiation dose to the skin surface in order to effectively treat the tumor. This issue is quite different when irradiating mucosal carcinomas of the head and neck (e.g., oropharynx, larynx) where minimizing radiation dose to the skin is desired. The added skin toxicity of combining chemotherapy in the setting of head and neck NMSC, is therefore, not known.

Our data suggest that the use of concomitant chemotherapy in the setting of non-skin-sparing radiation treatment in the head and neck is feasible with acceptable skin toxicity since radiation treatment breaks from excessive skin toxicity were rare. In our series, the rate of severe radiation dermatitis was only $13 \%$, which is somewhat surprising since we expected higher rates when tissue-equivalent bolus was used in the majority $(75 \%)$ of patients. It is likely that the toxicity rates may have been underestimated due to the retrospective nature of clinical record reviews. Clinicians may have been reporting only acute skin toxicity outside the target volume regions. In addition, clinicians may have had difficulty in assessing in-field radiation dermatitis in these patients. Because the treated tumors frequently encompass significant portions of the radiation treatment fields, it may have been difficult to differentiate between in-field dermatitis and tumor necrosis. 
TABLE 3: Univariate and multivariate hazard ratios of relapse free survival.

\begin{tabular}{|c|c|c|c|c|c|}
\hline \multicolumn{3}{|c|}{ Univariate } & \multicolumn{3}{|c|}{ Multivariate } \\
\hline Factor & $\operatorname{HR}(95 \% \mathrm{CI})$ & $P$ value & Factor & $\operatorname{HR}(95 \% \mathrm{CI})$ & $P$ value \\
\hline Basal cell histology & $0.61(0.3-1.3)$ & 0.40 & Bone invasion & $9.43(2.8-32)$ & $<0.01$ \\
\hline Well-differentiated & $0.93(0.4-2.2)$ & 0.93 & Radiation alone & $2.72(7.9-9.3)$ & 0.11 \\
\hline T4 disease & $0.83(0.4-1.7)$ & 0.72 & Nodal disease & $2.60(1.3-5.1)$ & 0.01 \\
\hline Unresectable & 0.84 & 0.76 & & & \\
\hline Local invasion & $2.25(1.0-4.8)$ & 0.17 & & & \\
\hline Bone & $5.25(2.5-11.1)$ & $<0.01$ & & & \\
\hline Nerves & $1.91(0.9-4.1)$ & 0.27 & & & \\
\hline Soft tissue & $1.21(0.6-2.5)$ & 0.73 & & & \\
\hline Nodal disease & $1.35(0.8-2.2)$ & 0.19 & & & \\
\hline Positive margins & $1.68(0.8-3.5)$ & 0.34 & & & \\
\hline Recurrence & $1.01(0.5-2.1)$ & 0.99 & & & \\
\hline Radiation alone & $0.71(0.3-1.5)$ & 0.53 & & & \\
\hline Radiation break & $2.04(0.9-4.6)$ & 0.27 & & & \\
\hline Chemotherapy missed* & $3.52(1.4-8.8)$ & 0.13 & & & \\
\hline
\end{tabular}

* Applicable to chemoradiotherapy patients. HR, hazard ratio; CI, confidence interval.

TABle 4: Patterns of failure in chemoradiotherapy patients.

\begin{tabular}{|c|c|c|c|c|c|c|c|c|}
\hline \multicolumn{2}{|c|}{ Patient primary site } & \multirow{2}{*}{$\begin{array}{c}\text { T stage } \\
\text { T4 }\end{array}$} & \multirow{2}{*}{$\begin{array}{c}\text { N status } \\
\text { N0 }\end{array}$} & \multirow{2}{*}{$\begin{array}{c}\text { Histology } \\
\text { BCC }\end{array}$} & \multirow{2}{*}{$\begin{array}{l}\text { Adverse features } \\
\text { Aggressive local } \\
\text { invasion }\end{array}$} & \multirow{2}{*}{$\begin{array}{c}\text { Type of failure } \\
\text { Local }\end{array}$} & \multirow{2}{*}{$\begin{array}{l}\text { Time to relapse (months) } \\
24\end{array}$} & \multirow{2}{*}{$\begin{array}{c}\text { Disease status } \\
\text { NED }\end{array}$} \\
\hline 1 & Neck & & & & & & & \\
\hline 2 & Nose & $\mathrm{T} 4$ & No & SCC & $\begin{array}{l}\text { Gross perineural } \\
\text { invasion, positive } \\
\text { margins }\end{array}$ & Local & 7 & DOD \\
\hline 3 & Cheek & $\mathrm{T} 4$ & No & SCC & Unresectable & Local & 6 & DOD \\
\hline 4 & Cheek & $\mathrm{T} 4$ & N1 & SCC & $\begin{array}{l}\text { Unresectable, nodal } \\
\text { involvement }\end{array}$ & Local + regional & 5 & DOD \\
\hline 5 & Scalp & $\mathrm{T} 3$ & N3 & SCC & Nodal involvement & Distant & 5 & DOD \\
\hline 6 & Ear & $\mathrm{T} 4$ & $\mathrm{~N} 2 \mathrm{~b}$ & SCC & $\begin{array}{l}\text { Unresectable, nodal } \\
\text { involvement }\end{array}$ & Distant & 9 & DOD \\
\hline
\end{tabular}

Abbreviations: BCC: basal cell carcinoma; SCC: squamous cell carcinoma; NED: no evidence of disease; DOD: died of disease.

Severe mucositis was rare ( 1 of 15 patients), which was expected in our patients because the majority of the radiation treatment volumes were focused on the skin or unilateral necks, thus, minimizing dose to the oral cavity and pharynx. Hematologic toxicity was also acceptable, primarily due to the use of lower chemotherapy doses in a weekly schedule in the majority of patients.

Due to the small numbers of patients in our study, conclusions cannot be drawn regarding the efficacy of this treatment approach in head and neck NMSCs. And due to the heterogeneity of patient characteristics between patients treated with CRT and RT alone, the therapeutic gain of the addition of chemotherapy to RT cannot be fully assessed in this study. Locoregional control rates with CRT, however, are encouraging, particularly given the high proportion of highrisk features in this patient group as shown in Table 1.

Our results in both the CRT- and RT-treated patients compare favorably with those reported in published literature. Institutional reviews of locally advanced T4 lesions treated with RT alone consistently showed initial local control rates from $50 \%$ to $75 \%$ for primary lesions $[3,11,12,14]$ and $41 \%$ to $50 \%$ for recurrent lesions $[3,11]$. Ultimate local control rates after salvage therapy in these studies range from $59 \%$ to $90 \%[11,14]$ but were frequently associated with significant morbidity. The locoregional control rate in our study was $70 \%$ for patients with T4 lesions treated with definitive CRT.

The main limitations of this study are the retrospective nature and small numbers of patients. However, to our knowledge, no other data other than case reports $[26,27]$ exist on the use of CRT for NMSC of the head and neck. Our experience provides initial data to support additional exploration of this treatment approach for high-risk head and neck NMSCs. Phase I and II studies combining RT with chemotherapy or targeted agents are appropriate to consider in these patients. Based on our institutional experience, a weekly cisplatin or carboplatin regimen would be reasonable to consider as concurrent chemotherapy platforms in future clinical trials, given the acceptable toxicity and ease of administration of these agents. The Trans-Tasman Radiation Oncology Group (TROG 05.01) is currently enrolling patients in a large phase III trial that randomizes resected 
high-risk (node positive or T3-4) cutaneous squamous cell carcinomas of the head and neck to adjuvant RT with or without concomitant weekly carboplatin. Results from this trial should provide important evidence on the benefit or lack of benefit of adding chemotherapy to RT in these patients. Antiepidermal growth factor (EGFR) agents such as cetuximab or erlotinib would be another approach to consider as radiosensitizing agents, because preliminary reports have suggested that the EGFR pathway may play an important role in the normal physiology of the cutaneous epidermis, [15] and potentially in NMSC metastatic disease $[34,35]$.

This study provides preliminary, hypothesis-generating data on the feasibility and tolerability of combining chemotherapy concomitantly with RT for the treatment of high-risk NMSCs of the head and neck. Our data also confirm previous reports that some patients with NMSC are at high-risk of death and recurrence for their disease. In the absence of proven efficacy, this type of multimodality treatment should at least be considered as an alternative aggressive treatment approach for locally advanced disease or tumors with nodal metastasis. At our institution, we generally consider utilizing concomitant CRT in patients that have unresectable disease (which often include patients with bone invasion) or those with positive margins or nodal disease after surgery. Before becoming a widely accepted treatment approach in these patients, further studies are needed to fully assess the toxicity and better define subsets of patients that may benefit from combined modality treatment.

\section{Disclosure}

J. Tepper, was a consultant for Varian.

\section{References}

[1] J. A. Neville, E. Welch, and D. J. Leffell, "Management of nonmelanoma skin cancer in 2007," Nature Clinical Practice Oncology, vol. 4, no. 8, pp. 462-469, 2007.

[2] D. R. English, B. K. Armstrong, A. Kricker, M. G. Winter, P. J. Heenan, and P. L. Randell, "Demographic characteristics, pigmentary and cutaneous risk factors for squamous cell carcinoma of the skin: a case-control study," International Journal of Cancer, vol. 76, no. 5, pp. 628-634, 1998.

[3] J. Locke, S. Karimpour, G. Young, M. A. Lockett, and C. A. Perez, "Radiotherapy for epithelial skin cancer," International Journal of Radiation Oncology Biology Physics, vol. 51, no. 3, pp. 748-755, 2001.

[4] I. Leibovitch, S. C. Huilgol, D. Selva, D. Hill, S. Richards, and R. Paver, "Cutaneous squamous cell carcinoma treated with Mohs micrographic surgery in Australia I. Experience over 10 years," Journal of the American Academy of Dermatology, vol. 53, no. 2, pp. 253-260, 2005.

[5] B. S. Cherpelis, C. Marcusen, and P. G. Lang, "Prognostic factors for metastasis in squamous cell carcinoma of the skin," Dermatologic Surgery, vol. 28, no. 3, pp. 268-273, 2002.

[6] K. D. Brantsch, C. Meisner, B. Schönfisch et al., "Analysis of risk factors determining prognosis of cutaneous squamouscell carcinoma: a prospective study," The Lancet Oncology, vol. 9, no. 8, pp. 713-720, 2008.
[7] M. J. Veness, C. E. Palme, and G. J. Morgan, "High-risk cutaneous squamous cell carcinoma of the head and neck: results from 266 treated patients with metastatic lymph node disease," Cancer, vol. 106, no. 11, pp. 2389-2396, 2006.

[8] J. T. Mullen, L. Feng, Y. Xing et al., "Invasive squamous cell carcinoma of the skin: defining a high-risk group," Annals of Surgical Oncology, vol. 13, no. 7, pp. 902-909, 2006.

[9] N. Audet, C. E. Palme, P. J. Gullane et al., "Cutaneous metastatic squamous cell carcinoma to the parotid gland: analysis and outcome," Head and Neck, vol. 26, no. 8, pp. 727-732, 2004.

[10] M. J. Veness, G. J. Morgan, C. E. Palme, and V. Gebski, "Surgery and adjuvant radiotherapy in patients with cutaneous head and neck squamous cell carcinoma metastatic to lymph nodes: combined treatment should be considered best practice," Laryngoscope, vol. 115, no. 5, pp. 870-875, 2005.

[11] W. R. Lee, W. M. Mendenhall, J. T. Parsons, and R. R. Million, "Radical radiotherapy for T4 carcinoma of the skin of the head and neck: a multivariate analysis," Head and Neck, vol. 15, no. 4, pp. 320-324, 1993.

[12] W. Kwan, D. Wilson, and V. Moravan, "Radiotherapy for locally advanced basal cell and squamous cell carcinomas of the skin," International Journal of Radiation Oncology Biology Physics, vol. 60, no. 2, pp. 406-411, 2004.

[13] J. A. D. Jol, M. L. F. van Velthuysen, F. J. M. Hilgers, R. B. Keus, H. Neering, and A. J. M. Balm, "Treatment results of regional metastasis from cutaneous head and neck squamous cell carcinoma," European Journal of Surgical Oncology, vol. 29, no. 1, pp. 81-86, 2003.

[14] M. O. F. Al-Othman, W. M. Mendenhall, and R. J. Amdur, "Radiotherapy alone for clinical T4 skin carcinoma of the head and neck with surgery reserved for salvage," American Journal of Otolaryngology - Head and Neck Medicine and Surgery, vol. 22, no. 6, pp. 387-390, 2001.

[15] D. G. Pfister and A. C. Halpern, "Skin squamous cell cancer: the time is right for greater involvement of the medical oncologist," Journal of Clinical Oncology, vol. 25, no. 15, pp. 19531954, 2007.

[16] A. A. Forastiere, H. Goepfert, M. Maor et al., "Concurrent chemotherapy and radiotherapy for organ preservation in advanced laryngeal cancer," New England Journal of Medicine, vol. 349, no. 22, pp. 2091-2098, 2003.

[17] F. Denis, P. Garaud, E. Bardet et al., "Final results of the 9401 French head and neck oncology and radiotherapy group randomized trial comparing radiotherapy alone with concomitant radiochemotherapy in advanced-stage oropharynx carcinoma," Journal of Clinical Oncology, vol. 22, no. 1, pp. 6976, 2004.

[18] J. S. Cooper, T. F. Pajak, A. A. Forastiere et al., "Postoperative concurrent radiotherapy and chemotherapy for high-risk squamous-cell carcinoma of the head and neck," New England Journal of Medicine, vol. 350, no. 19, pp. 1937-1944, 2004.

[19] D. J. Adelstein, Y. Li, G. L. Adams et al., "An intergroup phase III comparison of standard radiation therapy and two schedules of concurrent chemoradiotherapy in patients with unresectable squamous cell head and neck cancer," Journal of Clinical Oncology, vol. 21, no. 1, pp. 92-98, 2003.

[20] J. S. Cooper, M. D. Guo, A. Herskovic et al., "Chemoradiotherapy of locally advanced esophageal cancer: long-term followup of a prospective randomized trial (RTOG 85-01)," Journal of the American Medical Association, vol. 281, no. 17, pp. 16231627, 1999.

[21] W. A. Peters, P. Y. Liu, R. J. Barrett et al., "Concurrent chemotherapy and pelvic radiation therapy compared with 
pelvic radiation therapy alone as adjuvant therapy after radical surgery in high-risk early-stage cancer of the cervix," Journal of Clinical Oncology, vol. 18, no. 8, pp. 1606-1613, 2000.

[22] M. Morris, P. J. Eifel, J. Lu et al., "Pelvic radiation with concurrent chemotherapy compared with pelvic and para-aortic radiation for high-risk cervical cancer," New England Journal of Medicine, vol. 340, no. 15, pp. 1137-1143, 1999.

[23] H. M. Keys, B. N. Bundy, F. B. Stehman et al., "Cisplatin, radiation, and adjuvant hysterectomy compared with radiation and adjuvant hysterectomy for bulky stage IB cervical carcinoma," New England Journal of Medicine, vol. 340, no. 15, pp. 1154 $1161,1999$.

[24] H. Bartelink, F. Roelofsen, F. Eschwege et al., "Concomitant radiotherapy and chemotherapy is superior to radiotherapy alone in the treatment of locally advanced anal cancer: results of a phase III randomized trial of the European organization for research and treatment of cancer radiotherapy and gastrointestinal cooperative groups," Journal of Clinical Oncology, vol. 15, no. 5, pp. 2040-2049, 1997.

[25] J. M. A. Northover, S. J. Arnott, D. Cunningham et al., "Epidermoid anal cancer: results from the UKCCCR randomised trial of radiotherapy alone versus radiotherapy, 5-fluorouracil, and mitomycin," Lancet, vol. 348, no. 9034, pp. 1049-1054, 1996.

[26] Y. Fujisawa, Y. Umebayashi, E. Ichikawa, Y. Kawachi, and F. Otsuka, "Chemoradiation using low-dose cisplatin and 5fluorouracil in locally advanced squamous cell carcinoma of the skin: a report of two cases," Journal of the American Academy of Dermatology, vol. 55, no. 5, supplement, pp. S81S85, 2006.

[27] J. S. Loeffler, D. A. Larson, and J. R. Clark, "Treatment of perineural metastasis from squamous carcinoma of the skin with aggressive combination chemotherapy and irradiation," Journal of Surgical Oncology, vol. 29, no. 3, pp. 181-183, 1985.

[28] F. L. Greene, D. L. Page, I. D. Fleming, and A. G. Fritz, AJCC Cancer Staging Manual, Springer, New York, NY, USA, 6th edition, 2002.

[29] J. D. Kalbfleisch and R. L. Prentice, The Statistical Analysis of Failure Time Data, John Wiley \& Sons, New York, NY, USA, 1980.

[30] R. J. Gray, "A class of K-sample tests for comparing the cumulative incidence of a competing risk," Annals of Statistics, vol. 16, pp. 1141-11454, 1988.

[31] E. Kaplan and P. Meier, "Nonparametric estimation from incomplete observations," Journal of the American Statistical Association, vol. 53, pp. 457-481, 1958.

[32] N. Mantel and W. Haenszel, "Statistical aspects of the analysis of data from retrospective studies of disease," Journal of the National Cancer Institute, vol. 22, no. 4, pp. 719-748, 1959.

[33] R. C. Gentleman, V. J. Carey, D. M. Bates et al., "Bioconductor: open software development for computational biology and bioinformatics," Genome Biology, vol. 5, no. 10, p. R80, 2004.

[34] E. Maubec, P. Duvillard, V. Velasco, B. Crickx, and M. F. Avril, "Immunohistochemical analysis of EGFR and HER-2 in patients with metastatic squamous cell carcinoma of the skin," Anticancer Research, vol. 25, no. 2 B, pp. 1205-1210, 2005.

[35] T. Shimizu, H. Izumi, A. Oga et al., "Epidermal growth factor receptor overexpression and genetic aberrations in metastatic squamous-cell carcinoma of the skin," Dermatology, vol. 202, no. 3, pp. 203-206, 2001. 


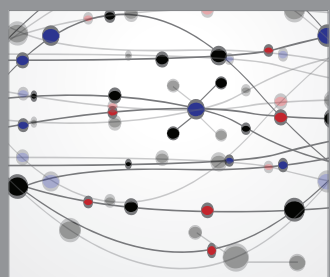

The Scientific World Journal
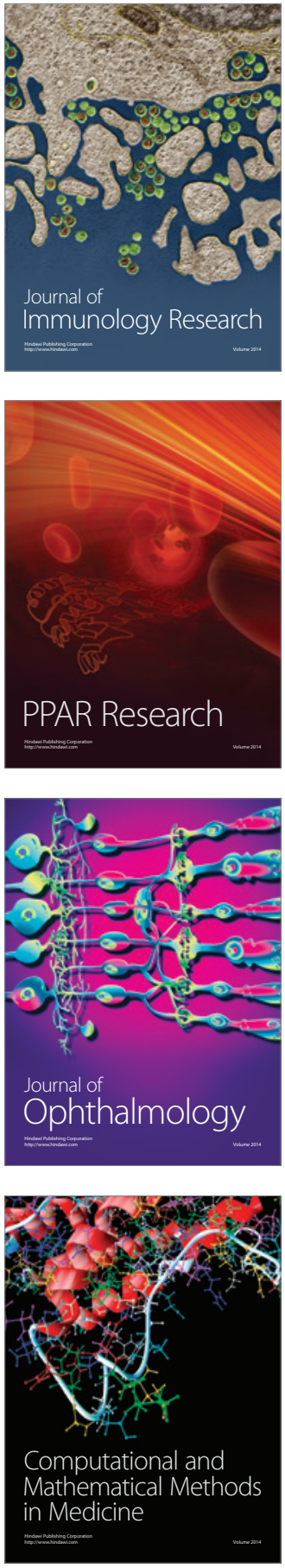

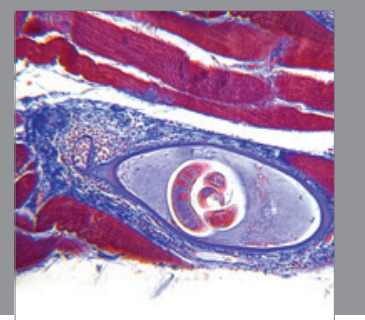

Gastroenterology

Research and Practice
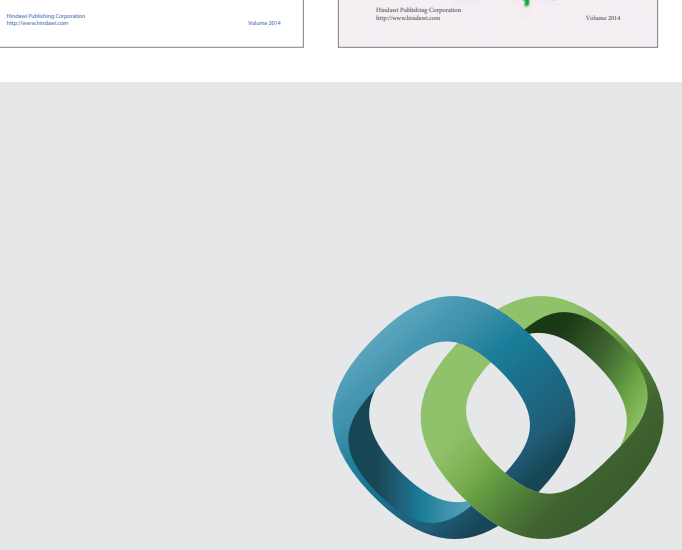

\section{Hindawi}

Submit your manuscripts at

http://www.hindawi.com
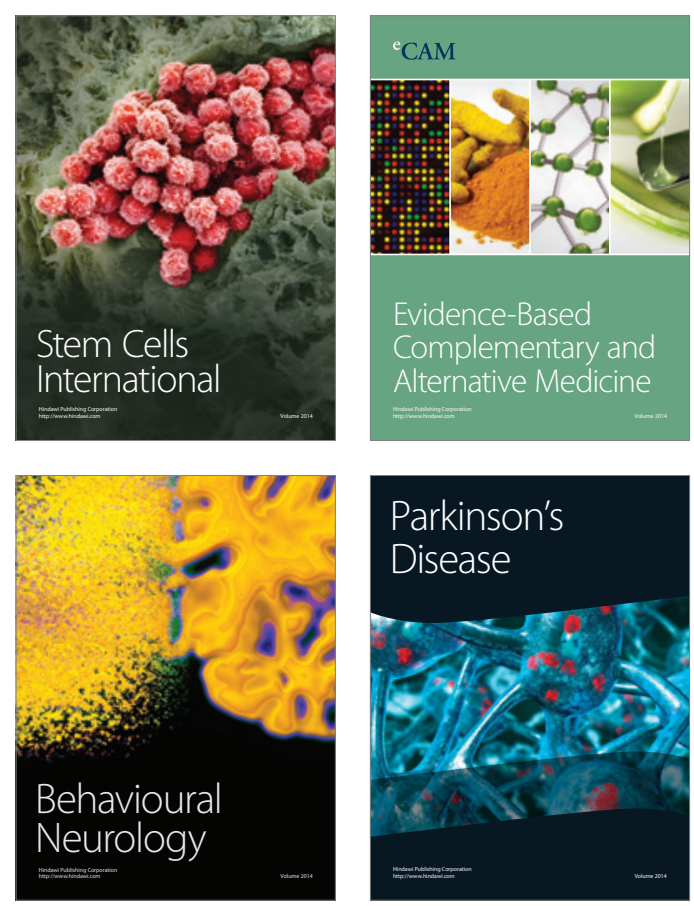

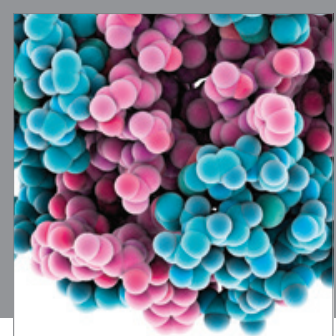

Journal of
Diabetes Research

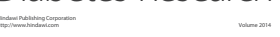

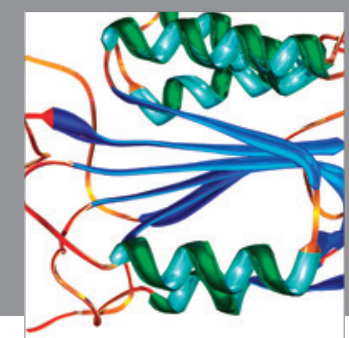

Disease Markers
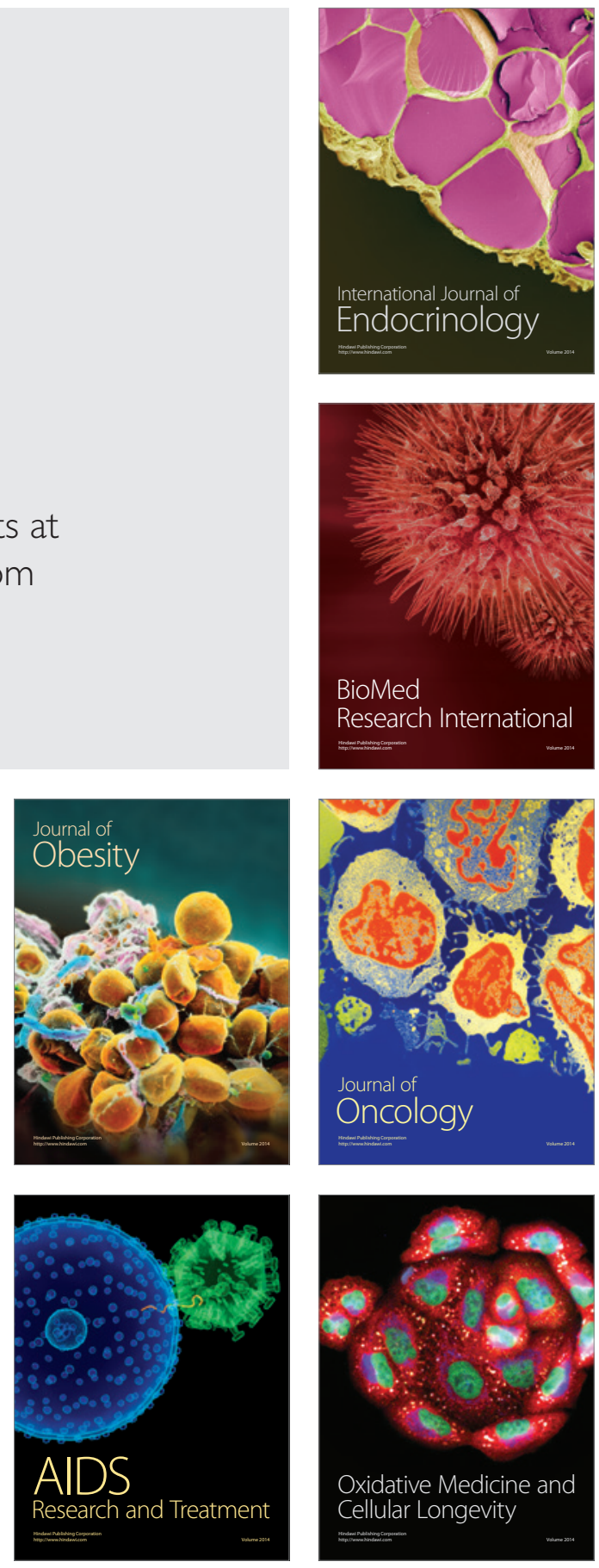